\title{
Curcumin inhibits the growth of liver cancer by impairing myeloid-derived suppressor cells in murine tumor tissues
}

\author{
SHA TIAN $^{1}$, LIU LIAO ${ }^{1}$, QING ZHOU ${ }^{2}$, XIAODI HUANG ${ }^{3}$, PIAO ZHENG $^{1}$, \\ YINMEI GUO ${ }^{1}$, TIANHAO DENG ${ }^{4}$ and XUEFEI TIAN ${ }^{1}$
}

\begin{abstract}
${ }^{1}$ Department of Internal Medicine, College of Integrated Chinese and Western Medicine of Hunan University of Chinese Medicine, Changsha, Hunan 410208; ${ }^{2}$ Department of Andrology, The First Affiliated Hospital of Hunan University of Chinese Medicine, Changsha, Hunan 410007; ${ }^{3}$ Hunan Key Laboratory of Traditional Chinese Medicine Prescription and Syndromes Translational Medicine, Hunan University of Chinese Medicine, Changsha, Hunan 410208; ${ }^{4}$ Department of Oncology, The Affiliated Hospital of Hunan Institute of Chinese Medicine, Changsha, Hunan 410006, P.R. China
\end{abstract}

Received July 14, 2020; Accepted January 14, 2021

DOI: 10.3892/ol.2021.12547

\begin{abstract}
Curcumin, one of the active ingredients of Curcuma longa (Jianghuang), has been reported to exert multiple bioactivities, including pro-apoptotic and anti-inflammatory activities. In recent years, curcumin has been extensively studied, and it has been revealed that curcumin inhibits the growth of numerous types of cancer. However, to the best of our knowledge, the inhibitory effects of curcumin on the activation or expansion of myeloid-derived suppressor cells (MDSCs) in liver cancer and the underlying mechanism have not yet been determined. Therefore, the present study aimed to investigate the inhibitory effect of curcumin on MDSC activity and the associated anti-neoplastic mechanism in a HepG2 xenograft mouse model. The effect of curcumin on the viability of Huh-7, MHCC-97H and HepG2 cells in vitro was analyzed using a Cell Counting Kit- 8 assay. The effects of curcumin on tumor growth, numbers of MDSCs, expression levels of proteins involved in the toll-like receptor 4 (TLR4)/NF- $\kappa \mathrm{B}$ signaling pathway, levels of related inflammatory factors and angiogenesis were determined in HepG2 xenograft model mice, which were given different doses of curcumin via intragastrical administration. The results of the present study revealed that curcumin inhibited the viability of Huh-7, MHCC-97H and HepG2 cells and the growth of HepG2 xenograft tumors in mice. Flow cytometric analysis indicated that curcumin reduced the number of MDSCs in mouse xenograft tumors. In addition, the results demonstrated that
\end{abstract}

Correspondence to: Professor Xuefei Tian, Department of Internal Medicine, College of Integrated Chinese and Western Medicine of Hunan University of Chinese Medicine, 300 Xueshi Road, Changsha, Hunan 410208, P.R. China

E-mail: txf1718@163.com

Key words: curcumin, liver cancer, myeloid-derived suppressor cells, toll-like receptor $4 / \mathrm{NF}-\kappa \mathrm{B}$, vascular endothelial growth factor curcumin inhibited the TLR4/NF- $\mathrm{B}$ signaling pathway and the expression of inflammatory factors, including IL-6, IL-1 $\beta$, prostaglandin E2 and cyclooxygenase-2, in mouse xenograft tumors. Furthermore, curcumin suppressed the secretion of granulocyte-macrophage colony-stimulating factor (GM-CSF) and granulocyte-colony stimulating factor (G-CSF), which are essential factors for MDSCs modulation, in tumor tissues. Additionally, curcumin was revealed to inhibit angiogenesis, which was demonstrated by the downregulation of the expression levels of vascular endothelial growth factor, CD31 and $\alpha$-smooth muscle actin in western blotting, immunohistochemistry and immunofluorescence experiments. In conclusion, the findings of the present study identified a novel mechanism via which curcumin may suppress the growth of liver cancer by reducing the numbers of MDSCs and subsequently disrupting the process of angiogenesis. These conclusions were supported by the observed inactivation of the TLR4/NF- $\kappa \mathrm{B}$ signaling pathway-mediated inflammatory response and the downregulation of GM-CSF and G-CSF secretion in xenograft tissues.

\section{Introduction}

Tumor-derived cytokines and growth factors have been reported to alter the process of hematopoiesis, which regulates the myeloid cell differentiation process, and to promote the proliferation and expansion of cells with immunosuppressive properties, namely myeloid-derived suppressor cells (MDSCs) $(1,2)$. MDSCs enhance tumor growth not only by shaping immune responses towards tumor tolerance, but also by supporting several processes required for the neoplastic progression, including tumor angiogenesis and cancer metastasis dissemination $(3,4)$.

Murine MDSCs have been identified to exclusively bear the markers CD11b (also known as integrin $\alpha \mathrm{M}$ ) and granulocyte receptor-1 (Gr-1; the anti-Gr-1 monoclonal antibody recognizes epitopes common to Ly6C and Ly6G) (5). Tumors have been reported to secrete a large array of tumor-derived factors (TDFs), which work synergistically to accelerate the accumulation of functional MDSCs (6). The three major regulators 
of the proliferation and differentiation of myeloid cells are macrophage colony-stimulating factor (M-CSF), granulocyte colony-stimulating factor (G-CSF) and granulocyte-macrophage colony-stimulating factor (GM-CSF), and these are produced by tumor cells and the tumor stroma (7). GM-CSF exhibits a dual role in cancer, since it has been identified to drive cell differentiation towards either an immunosuppressive (involving MDSCs) or immunostimulatory (involving dendritic cells) phenotype, depending on the strength of the stimulus and the overall cytokine landscape $(8,9)$. G-CSF has been reported to promote the differentiation of myeloid precursors to polymorphonuclear-MDSCs and to stimulate their preferential recruitment towards tumors $(10,11)$. Therefore, GM-CSF and G-CSF may serve a crucial role in MDSC activation and the progression of tumorigenesis, and altering their levels with targeted compounds may represent a potential therapeutic strategy.

Inflammation in solid tumors has been demonstrated to enhance cancer growth and metastasis (12). Sustained inflammation is associated with not only the activation of the $\mathrm{NF}-\kappa \mathrm{B}$ signaling pathway in cancer cells, but also the recruitment of immature myeloid derived cells (such as MDSCs) (13). In cancer cells, overactive $\mathrm{NF}-\kappa \mathrm{B}$ has been demonstrated to promote the excessive production of pro-inflammatory cytokines, such as IL-6, IL-1 $\beta$ and TNF- $\alpha$, which establishes an inflammatory microenvironment and recruits MDSCs (14). Recruited MDSCs have been demonstrated to further secrete pro-inflammatory cytokines, causing a vicious circle, while also participating in angiogenesis and immune tolerance (15-17). Toll-like receptors (TLRs) have crucial roles in inflammation and cancer, and proteins downstream of the receptors, such as myeloid differentiation primary response 88 (MyD88) and NF- $\kappa \mathrm{B}$, enable cancer cells to escape from the immune system, which contributes to cancer progression (18). Notably, the inhibition of the NF- $\mathrm{B}$-mediated secretion of pro-inflammatory cytokines, including TNF- $\alpha$, IL-6, IL-8, IL-1 $\beta$ and IL-4, has been revealed to decrease the volume of xenograft tumors and the accumulation of MDSCs (19). Therefore, blocking the TLR4/NF- $\kappa \mathrm{B}$ signaling pathway and inhibiting MDSC recruitment may be an effective strategy for the treatment of numerous types of cancer.

Curcumin, a diketone compound, can be isolated from the rhizomes of the plant Curcuma longa. The anticancer effects of curcumin have been established through multiple in vivo and in vitro studies $(20,21)$. Curcumin exhibits pharmacological activities and has been demonstrated to exert beneficial health effects through its ability to regulate cancer cell proliferation (20), tumor growth (21), apoptosis (22), migration, invasion, angiogenesis, metastasis, bioenergetics (23), oxidation (24) and the inflammatory environment $(25,26)$. Previous studies have demonstrated that curcumin prevents cancer progression through its antioxidant, anti-inflammatory and immunoregulatory properties (27-30). Although the anticancer properties of curcumin have been extensively investigated, whether its effects are mediated by modulating MDSCs and the mechanism by which MDSCs are regulated remains elusive. Based on the aforementioned findings, it was hypothesized that curcumin may inhibit MDSC-mediated angiogenesis and immune tolerance in liver cancer by attenuating the TLR4/NF- $\mathrm{B}$-induced inflammatory microenvironment and reducing the levels of GM-CSF and G-CSF.

\section{Materials and methods}

Drugs and reagents. Curcumin (batch number, SLBN7214V; molecular weight, $368.39 \mathrm{kDa}$ ) was purchased from Sigma-Aldrich; Merck KGaA. Fluorouracil (5-Fu; batch number, FA170415) was obtained from Shanghai Xudong Haipu Pharmaceutical Co., Ltd., and cisplatin (DDP; batch number, 8A0075B02) was purchased from Qilu Pharmaceutical Co., Ltd. The anti-CD11b-PE/Cy7 (cat.no. ab218786) and anti-Gr-1-FITC (cat. no. ab25024) antibodies were purchased from Abcam. PBS, DMEM and BSA were purchased from Sigma-Aldrich; Merck KGaA. HRP-conjugated goat anti-mouse IgG antibody (cat. no. SA00001-1), HRP-conjugated goat anti-rabbit IgG antibody (cat. no. SA00001-2) and HRP-conjugated donkey anti-goat IgG antibody (cat. no. SA00001-3) were purchased from ProteinTech Group, Inc. Protease inhibitors and protein phosphatase inhibitors were purchased from Roche Diagnostics.

Cell culture. The human liver cancer cell lines (HepG2, Huh-7 and MHCC-97H) were purchased from The Cell Bank of Type Culture Collection of The Chinese Academy of Sciences and stored at the Cell Center of Xiangya Medical College of Central South University (Changsha, China). The cells were cultured in DMEM supplemented with 10\% FBS (Gibco; Thermo Fisher Scientific, Inc.) and 1X penicillin/streptomycin, and maintained in a humified atmosphere at $37^{\circ} \mathrm{C}$ with $5 \% \mathrm{CO}_{2}$. Curcumin was dissolved in DMSO to make a $9.6 \mathrm{mg} / \mathrm{ml}$ stock solution. HepG2, Huh-7 and MHCC-97H cells were co-incubated with curcumin $(1.2,2.4,4.8$ or $9.6 \mu \mathrm{g} / \mathrm{ml})$ for 24 and $48 \mathrm{~h}$ at $37^{\circ} \mathrm{C}$. In addition, HepG 2 cells in the exponential growth phase were transplanted into mice to generate tumors as described subsequently.

Cell Counting Kit-8 (CCK-8) assay. Huh-7, MHCC-97H and HepG2 cells were seeded into 96-well plates at a density of 4,000 cells/well. Once attached, the cells were treated with $1.2,2.4,4.8$ or $9.6 \mu \mathrm{g} / \mathrm{ml}$ curcumin for 24 or $48 \mathrm{~h}$ at $37^{\circ} \mathrm{C}$. Cell viability was analyzed using CCK-8 reagent (cat. no. C0038; Beyotime Institute of Biotechnology) according to the manufacturer's protocol. Briefly, $10 \mu \mathrm{l}$ CCK-8 reagent was added into each well, and cells were incubated for $1 \mathrm{~h}$ in the dark. Subsequently, the absorbance was measured at a wavelength of $450 \mathrm{~nm}$ using a microplate reader (BioTek Instruments, Inc.).

Flow cytometry. The cells were collected by trypsinization and adjusted to a density of $3 \times 10^{5}$ cells $/ \mathrm{ml}$. The cell samples were washed twice with $\mathrm{PBS}$ via centrifugation for $10 \mathrm{~min}$ at $1,000 \mathrm{x} \mathrm{g}$ at $4^{\circ} \mathrm{C}$, and resuspended in $1 \mu \mathrm{g}$ anti-CD11b-PE/Cy7 (dilution, 1:100) and anti-Gr-1-FITC (dilution, 1:100) antibodies. Following $30 \mathrm{~min}$ of incubation at $37^{\circ} \mathrm{C}$ in the dark, the samples were performed on a Gallios flow cytometer (Beckman Coulter, Inc.) and analyzed using FlowJo V.10 software (Tree Star, Inc.). MDSCs were identified based on double positivity for CD11b and Gr-1. 
Xenograft experiments. BALB/c-nu nude mice [specific pathogen-free (SPF) grade; male; weight, 18-22 g; age, 21-28 days] were provided by Hunan SJA Laboratory Animal Co., Ltd. Mice were raised in an animal room (SPF grade) at Xiangya Medical College (Changsha, China). The animal experiment protocols were performed in accordance with the National Institutes of Health Guide for the Care and Use of Laboratory Animals (2011) (31) and approved by the Animal Research Ethics Committee of Central South University (approval no. 2018SYNKW0181; Changsha, China). A total of 28 mice were maintained at $25.0 \pm 2.0^{\circ} \mathrm{C}$ and $55.0 \pm 5.0 \%$ relative humidity with a 12-h light/dark cycle, and ad libitum access to food and water. Following acclimation for 1 week, $1 \times 10^{7} \mathrm{HepG} 2$ cells in $0.1 \mathrm{ml}$ saline were injected into the right flank from the back of the mice to form subcutaneous xenograft tumors. Mice were divided into the following 4 groups ( $\mathrm{n}=7$ /group) on the 5 th day after injection when the tumor volume of HepG2 cells reached $\sim 50 \mathrm{~mm}^{3}$ : i) Model group (injected with cancer cells and administered intragastrically with the equivalent volume of $0.5 \%$ carboxymethylcellulose sodium, served as the negative control); ii) curcumin low dose group (Cur L; injected with cancer cells and administered intragastrically with $120 \mathrm{mg} / \mathrm{kg}$ curcumin daily); iii) curcumin high dose group (Cur $\mathrm{H}$; injected with cancer cells and administered intragastrically with $240 \mathrm{mg} / \mathrm{kg}$ curcumin daily); and iv) chemotherapy group (injected with cancer cells and intraperitoneally injected with $50 \mathrm{mg} / \mathrm{kg} 5-\mathrm{Fu}+5 \mathrm{mg} / \mathrm{kg}$ DDP once a week; positive control). The regimens of 5-Fu+DDP and curcumin were based on their clinical application and a previous study, respectively $(32,33)$. Furthermore, $240 \mathrm{mg} / \mathrm{kg}$ curcumin used in mice is equivalent to $\sim 1.3 \mathrm{~g} / \mathrm{day}$ in humans based on the body surface area $\left(\mathrm{m}^{2} / \mathrm{kg}\right)$ conversion between humans and mice, with a postulated adult body weight of $75 \mathrm{~kg}$ (human dosage $=(240 \mathrm{mg} / \mathrm{kg} / 14.16) \times 75 \mathrm{~kg})$, which was considered safe for humans according to a phase I clinical trial (34). The body weight and tumor volume of each mouse were measured every 3 days over a period of 15 days. The tumor volume was calculated using the following equation: Tumor volume=length $\mathrm{x}$ width $\mathrm{x}$ width/2. Animals were euthanized when $>20 \%$ of weight loss was recorded, tumors were $1.0-1.5 \mathrm{~cm}$ in diameter or severe disease signs (e.g., difficulty breathing or paralysis) were observed. On day 15 , a total of 28 mice ( $\mathrm{n}=7 /$ group) were sacrificed by intraperitoneal injection with an overdose of sodium pentobarbital $(200 \mathrm{mg} / \mathrm{kg})$, followed by cervical dislocation and rigor mortis as confirmation of death. The duration between injection and final tumor growth measurement was 20 days. The tumor tissues were removed, weighed and immediately stored at $-80^{\circ} \mathrm{C}$ for further analysis. The maximum tumor diameter and volume observed in the present study was $15.83 \mathrm{~mm}$ and $516.32 \mathrm{~mm}^{3}$, respectively.

Western blotting. Total protein was extracted from tissues using $200 \mu \mathrm{l}$ RIPA lysis buffer (Beyotime Institute of Biotechnology). Total protein was quantified by BCA and proteins $(50 \mu \mathrm{g} / \mathrm{lane})$ were separated via 10-12\% SDS-PAGE and distinguished according to their molecular weights: TLR4, $75 \mathrm{kDa}$; TNF- $\alpha, 17 \mathrm{kDa}$; nuclear factor- $\kappa \mathrm{B}$ kinase $\alpha$ (IKK $\alpha$ ), $88 \mathrm{kDa}$; nuclear factor-кB kinase $\beta$ (IKK $\beta$ ), $85 \mathrm{kDa}$; phosphorylated (p-)IKK $\alpha, 88 \mathrm{kDa}$; p-IKK $\beta, 85 \mathrm{kDa}$; NF-кB,
$65 \mathrm{kDa}$; MyD88, 33 kDa; IL-6, 24 kDa; IL-1ß, 35 kDa; prostaglandin E2 (PGE2), $53 \mathrm{kDa}$; cyclooxygenase-2 (COX-2), $74 \mathrm{kDa}$; vascular endothelial growth factor (VEGF), $25 \mathrm{kDa}$; and $\beta$-actin, $42 \mathrm{kDa}$. The separated proteins were subsequently transferred onto nitrocellulose membranes, which were blocked with 5\% BSA at room temperature for $2 \mathrm{~h}$ and incubated with the following primary antibodies at $4^{\circ} \mathrm{C}$ overnight: Anti-TLR4 (dilution, 1:700; cat. no. ab13556; Abcam), anti-TNF- $\alpha$ (dilution, 1:2,000; cat. no. 17590-1-AP; ProteinTech Group, Inc.), anti-IKK $\alpha$ (dilution, 1:10,000; cat. no. ab32041; Abcam), anti-IKK $\beta$ (dilution, 1:200; cat. no. 15649-1-AP; ProteinTech Group, Inc.), anti-p-IKK $\alpha$ (dilution, 1:500; cat. no. ab38515; Abcam), anti-p-IKK $\beta$ (dilution, 1:500; cat. no. ab59195; Abcam), anti-NF-кB (dilution, 1:500; cat. no. 10745-1-AP; ProteinTech Group, Inc.), anti-MyD88 (dilution, 1:500; cat. no. 23230-1-AP; ProteinTech Group, Inc.), anti-IL-6 (dilution, 1:500; cat. no. 21865-1-AP; ProteinTech Group, Inc.), anti-IL-1 $\beta$ (dilution, 1:200; cat. no. 16806-1-AP; ProteinTech Group, Inc.), anti-PGE2 (dilution, 1:1,000; cat. no. ab2318; Abcam), anti-COX-2 (dilution, 1:500; cat. no. 12375-1-AP; ProteinTech Group, Inc.), anti-VEGF (dilution, 1:500; cat. no. 19003-1-AP; ProteinTech Group, Inc.) and $\beta$-actin (dilution, 1:5,000; cat. no. 60008-1-Ig; ProteinTech Group, Inc.). Following the primary antibody incubation, the membranes were incubated with anti-rabbit secondary antibody (dilution, 1:6,000; cat. no. A0208; Beyotime Institute of Biotechnology) or HRP-conjugated goat anti-mouse IgG antibody (dilution, 1:500; cat. no. SA00001-1; ProteinTech Group, Inc.) for $1 \mathrm{~h}$ at room temperature. The protein bands were visualized using an ECL Western Blotting Substrate kit (cat. no. P0018FS; Beyotime Institute of Biotechnology). Bands were semi-quantified using ImageJ software (ImageJ 1.8.0; National Institutes of Health).

ELIAS assay. Mouse Granulocyte Colony Stimulating Factor and mouse Granulocyte Macrophage Colony Stimulating Factor ELISA kits were respectively used to determine G-CSF (cat. no. CSB-E04564m; Cusabio Biotech Co., Ltd.) and GM-CSF levels (cat. no. CSB-E04569m; Cusabio Biotech Co., Ltd.) in tumor tissues according to the manufacturer's protocols.

Immunohistochemistry (IHC) staining. The tumor tissues were fixed in $10 \%$ neutral buffered formalin for $24 \mathrm{~h}$ at room temperature, and then embedded in paraffin. The paraffin-embedded tumor tissue sections (thickness, $5 \mu \mathrm{m}$ ) were deparaffinized in xylene, rehydrated using an ascending series of alcohol in the following sequence: $100 \%$ ethanol for $3 \mathrm{~min}, 90 \%$ ethanol for $3 \mathrm{~min}, 80 \%$ ethanol for $3 \mathrm{~min}$ and $70 \%$ ethanol for $3 \mathrm{~min}$ and subsequently flushed with distilled water, followed by washing thoroughly with $0.01 \mathrm{M} \mathrm{PBS}$ (pH 7.2-7.6). For antigen retrieval, trypsin antigen retrieval solution was directly pipetted onto the tissue on the slide for $10 \mathrm{~min}$ at $37^{\circ} \mathrm{C}$. Subsequently, endogenous peroxidase activity was quenched by a 30-min incubation in methanolic hydrogen peroxide (2.5\%). After being sealed with 5\% BSA for $1 \mathrm{~h}$ at room temperature, the slides were incubated overnight at $4^{\circ} \mathrm{C}$ with the following primary antibodies: Anti-CD31 (dilution, 1:500; cat. no. 11265-1-AP; ProteinTech Group, Inc.), anti- $\alpha$-smooth muscle actin ( $\alpha$ SMC; dilution, 1:300; cat. no. ab21027; 

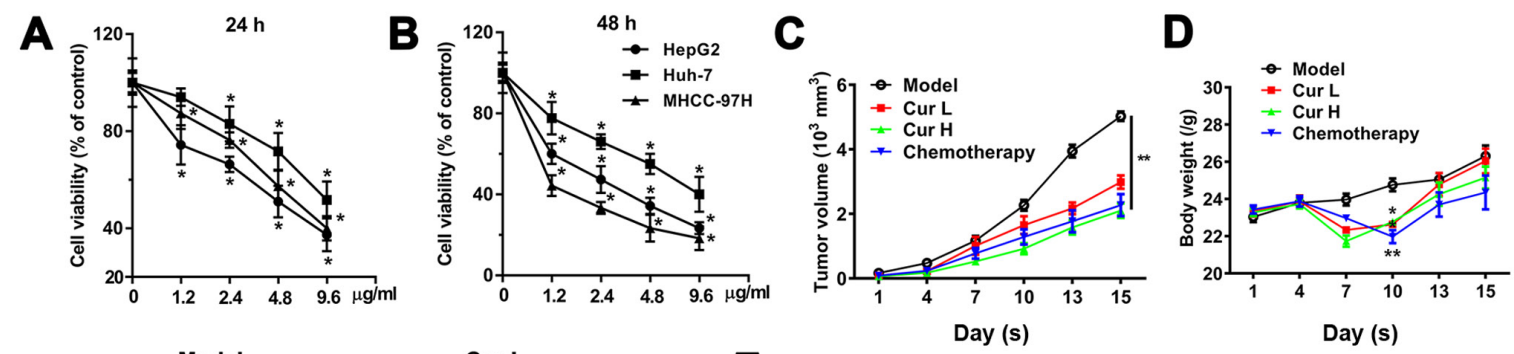
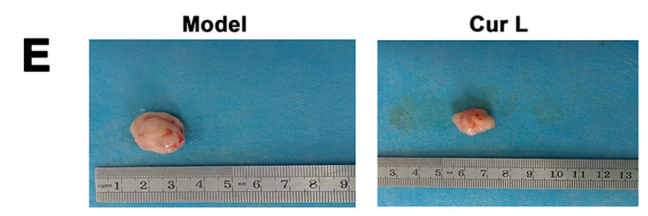

Cur H
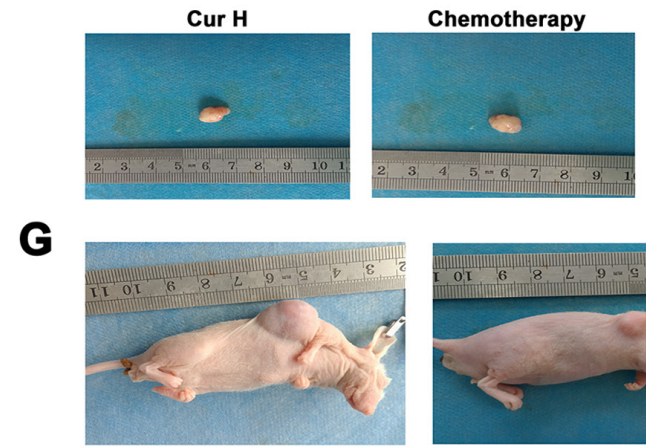

H

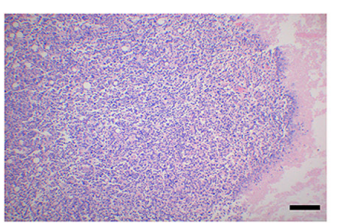

Model
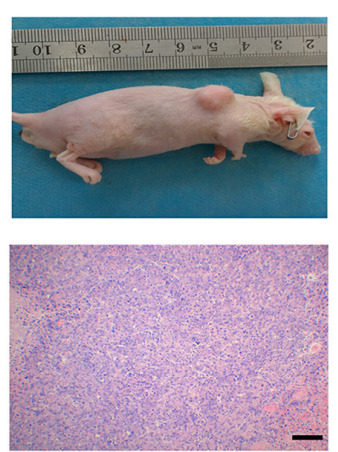

Cur L
$\mathbf{F}$

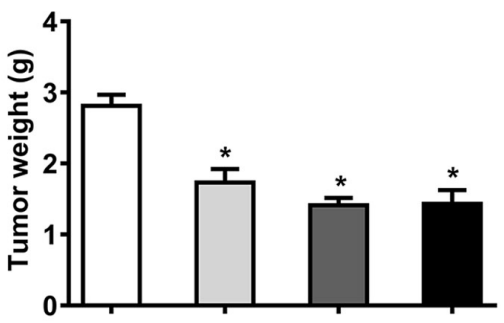

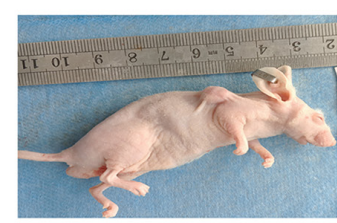

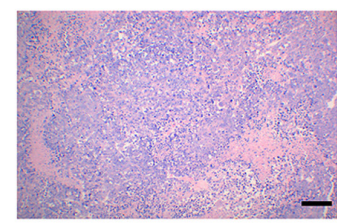

Cur H
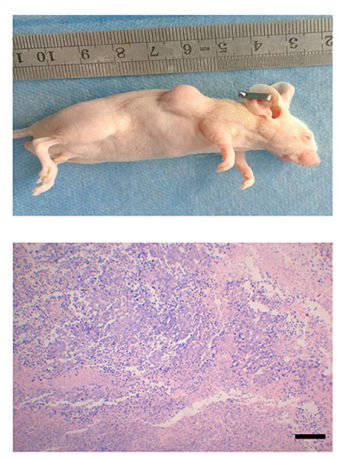

Chemotherapy

Figure 1. Curcumin suppresses liver cancer growth in vivo and in vitro. Viability of HepG2, Huh-7 and MHCC-97H cells following curcumin treatment at (A) 24 and (B) $48 \mathrm{~h}$. The $\mathrm{x}$-axis presents the concentration of curcumin ( $\mu \mathrm{g} / \mathrm{ml}$ ). Effects of curcumin on (C) tumor volume and (D) body weight were measured every 3 days. (E) Representative images of excised tumors in each group. (F) Weight of tumor tissues on day 15. (G) Representative images of nude mice with tumor xenografts in each group. (H) Hematoxylin and eosin staining of tumor tissues (magnification, x100; scale bar, $200 \mu \mathrm{m})$. Data are presented as the mean $\pm \mathrm{SD}(\mathrm{n}=7)$. ${ }^{*} \mathrm{P}<0.05$ and ${ }^{* *} \mathrm{P}<0.01$ vs. model group or vehicle control in CCK-8 assay. Cur L, curcumin low dose group (120 mg/kg); Cur H, curcumin high dose group $(240 \mathrm{mg} / \mathrm{kg})$.

Abcam) and anti-VEGF (dilution, 1:500; cat. no. 19003-1-AP; ProteinTech Group, Inc.). Following the primary antibody incubation, the sections were incubated with the corresponding HRP-conjugated anti-rabbit secondary antibody (dilution, 1:500; cat. no. A0208; Beyotime Institute of Biotechnology) or HRP-conjugated donkey anti-goat IgG antibody (dilution, 1:500; cat. no. SA00001-3; ProteinTech Group, Inc.) at $37^{\circ} \mathrm{C}$ for $30 \mathrm{~min}$. Subsequently, the slides were stained with 3,3'-diaminobenzidine at $25^{\circ} \mathrm{C}$ for $5 \mathrm{~min}$. All sections were observed under a light or fluorescence microscope (magnification, $\mathrm{x} 400$ ) and analyzed using HistoQuest 4.0 software (TissueGnostics $\mathrm{GmbH}$ ) as previously described (35).

Statistical analysis. Statistical analysis was performed using SPSS version 21.0 software (IBM Corp.) and the results are presented as the mean $\pm \mathrm{SD}$, except cell viability assay data which are presented as the mean \pm SEM. All data were from at least three independent triplicate experiments. Statistical differences among groups were analyzed using one-way ANOVA followed by Tukey's multiple comparisons test and the normality of data was determined using a
Kolmogorov-Smirnov test. $\mathrm{P}<0.05$ was considered to indicate a statistically significant difference.

\section{Results}

Curcumin inhibits the viability of liver cancer cells. To investigate the role of curcumin in regulating liver cancer cell proliferation, the effects of treatment with $1.2-9.6 \mu \mathrm{g} / \mathrm{ml}$ curcumin on the viability of Huh-7, MHCC-97H and HepG2 cells were determined. The results revealed a dose-dependent reduction in cell viability following 24 and $48 \mathrm{~h}$ of treatment (Fig. 1A and B). To verify the results in vivo, a HepG2 xenograft nude mouse model was used. Similarly, 120 and $240 \mathrm{mg} / \mathrm{kg} /$ day curcumin progressively decreased the tumor volume compared with the model group, which was measured for 15 days (Fig. 1C). Treatment with curcumin was observed to cause a decrease in body weight on the 10th day; however, the body weight subsequently increased and was not affected by curcumin treatment by the 15th day (Fig. 1D). As expected, the curcumin-induced decline in tumor volume was also associated with a marked decrease in tumor weight, revealing 

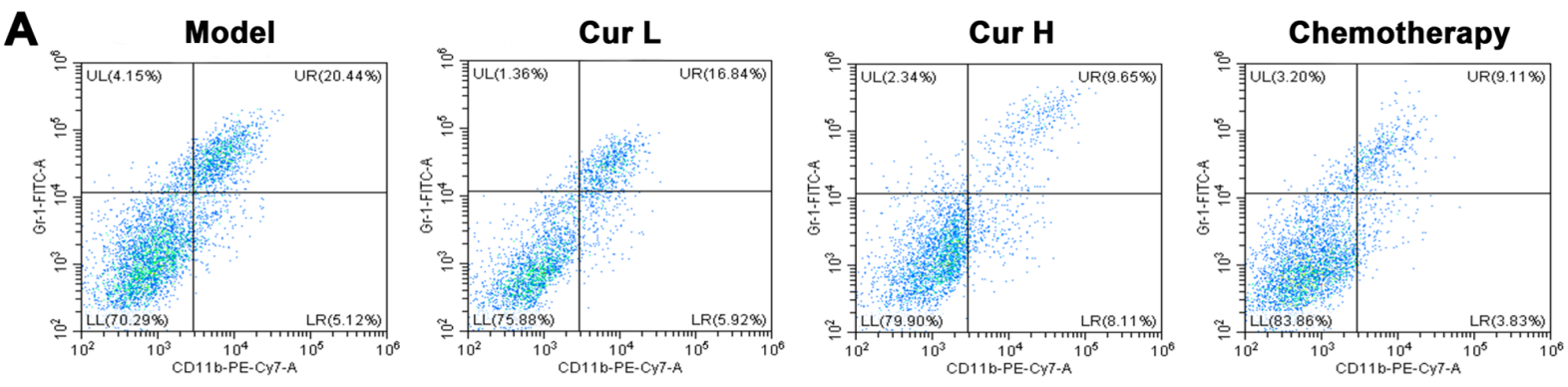

B

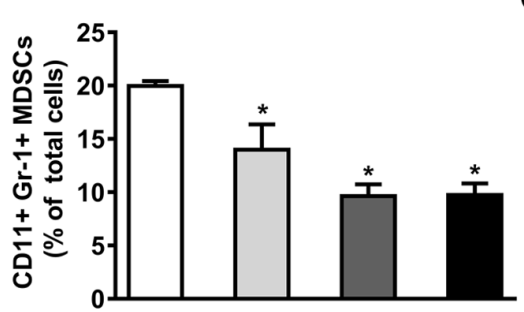

C

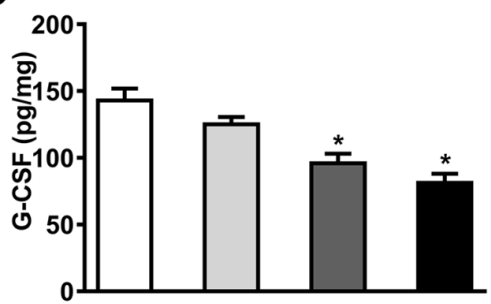

D

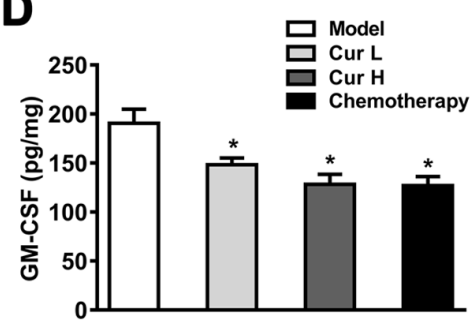

Figure 2. Curcumin inhibits MDSCs in tumor tissues. (A) Flow cytometric analysis of CD11b $/ \mathrm{Gr}^{-} 1^{+}$cells in murine tumor tissues. (B) Quantitative analysis of MDSCs in murine tumor tissue. Secretory levels of (C) G-CSF and (D) GM-CSF in the tumor tissues were measured using ELISAs. Tumor tissue samples were collected within $24 \mathrm{~h}$ following the attenuation of treatment with all drugs. Data are presented as the mean $\pm \mathrm{SD}$ ( $\mathrm{n}=7$ ). $\mathrm{P}<0.05 \mathrm{vs}$. model group. MDSCs, myeloid-derived suppressor cells; GM-CSF, granulocyte-macrophage colony-stimulating factor; G-CSF, granulocyte-colony-stimulating factor; Cur L, curcumin low dose group (120 mg/kg); Cur H, curcumin high dose group (240 mg/kg); Gr-1, granulocyte receptor-1; UL, upper left; UR, upper right; LL, lower left; LR, lower right.

comparable tumor growth inhibition efficacy between curcumin and chemotherapy treatments, which indicated the therapeutic potential of curcumin in liver cancer (Fig. 1F). The evaluation of tumor histology using hematoxylin and eosin staining indicated that the groups treated with curcumin (120 and $240 \mathrm{mg} / \mathrm{kg} /$ day) and the chemotherapy treatment group exhibited necrosis and lower cellularity compared with the model group (Fig. 1H). As shown in Fig. 1E and G, the in vivo and ex vivo images of the tumors further indicated the tumor-suppressive effects of curcumin.

Curcumin suppresses MDSCs and the secretion of modulatory-related factors GM-CSF and G-CSF. MDSCs serve a crucial role in the immunology of the majority of tumors, and are responsible for inhibiting the immune function of $\mathrm{T}$ cells and promoting angiogenesis (36). It was hypothesized that curcumin may inhibit the expansion of MDSCs, which would subsequently enhance immune function. To test this hypothesis, flow cytometry was used to determine $\mathrm{CD} 11 \mathrm{~b}^{+} \mathrm{Gr}-\mathrm{1}^{+}$expression in mouse xenograft tumor tissues. As shown in Fig. 2A and B, compared with the model group, treatment with 120 or $240 \mathrm{mg} / \mathrm{kg}$ curcumin or chemotherapy significantly reduced the percentage of MDSCs (in 7 mice). Notably, the treatment with curcumin at both a low $(120 \mathrm{mg} / \mathrm{kg})$ and high $(240 \mathrm{mg} / \mathrm{kg})$ dose exhibited a comparable inhibitory effect on MDSCs, suggesting that there were no dose-dependent effects when comparing low and high doses of curcumin. These results suggested that curcumin may inhibit the expansion of MDSCs in mice xenograft tumor tissues, but not in a dose-dependent manner.

To investigate whether the inhibitory effect of curcumin on MDSCs could be attributed to M-CSF and GM-CSF secretion, ELISAs were used to determine the secretory levels of GM-CSF and G-CSF. As illustrated in Fig. 2C and D, treatment with Cur H and chemotherapy notably reduced G-CSF and GM-CSF levels compared with the model group, whereas Cur L only significantly decreased GM-CSF levels. These data indicated that curcumin may suppress M-CSF and GM-CSF secretion, which could lead to the inactivation of MDSCs, and thereby restrict cancer cell proliferation.

Alterations in the expression levels of TLR $4 / N F-\kappa B$ signaling pathway-related proteins account for the inhibition of MDSCs. To investigate the latent molecular mechanism underlying the curcumin-modulated activity of MDSCs, the expression levels of proteins associated with the TLR4/NF- $\kappa \mathrm{B}$ signaling pathway were analyzed using western blotting. The results revealed that both curcumin and chemotherapy treatment significantly decreased TLR4, MyD88, p-IKK $\alpha /$ IKK $\alpha$, p-IKK $\beta /$ IKK $\beta$ and $\mathrm{NF}-\kappa \mathrm{B}$ expression compared with the model group. Notably, high doses of curcumin (Cur $\mathrm{H}$ ) exhibited greater effects than the treatment with chemotherapy in terms of the inhibition of the TLR4/NF- $\kappa \mathrm{B}$ signaling pathway, except the ratios of p-IKK $\alpha / \mathrm{IKK} \alpha$ and $\mathrm{p}-\mathrm{IKK} \beta / \mathrm{IKK} \beta$ (Fig. 3A-E). Considering that the TLR4/NF- $\mathrm{B}$ signaling pathway is the major inflammatory signaling pathway that mediates the expression levels of numerous inflammatory cytokines in cancer (37), and that inflammation serves an important role in cancer progression and MDSC recruitment and activation (38), the expression levels of TNF- $\alpha$, IL-6, IL-1 $\beta$, PGE2 and COX-2 in xenograft tumor tissues were analyzed. As shown in Fig. 3, treatment with curcumin at two doses (Cur L and Cur H) and chemotherapy significantly blocked the increased expression of TNF- $\alpha$, IL-6, IL-1 $\beta$, PGE2 and COX-2 compared with the model group (Fig. 3F-I). Notably, Cur $\mathrm{H}$ was at least comparable or superior to the chemotherapy treatment in terms of its ability to downregulate the expression levels of the proteins. These data indicated that curcumin may suppress the TLR4/NF- $\kappa \mathrm{B}$ 
A

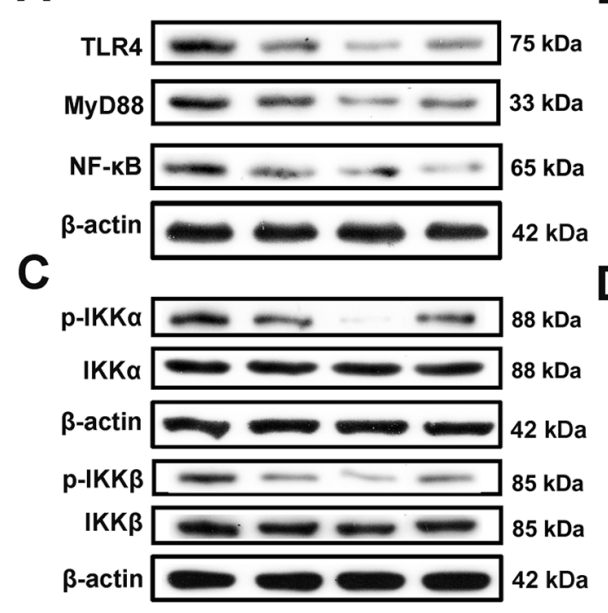

F

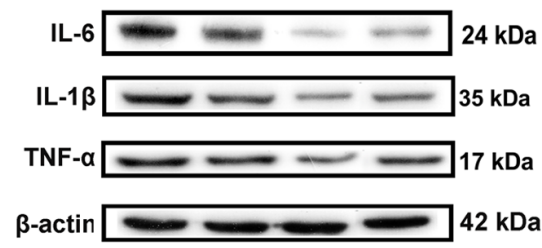

H

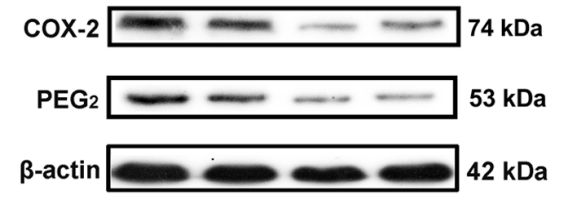

B

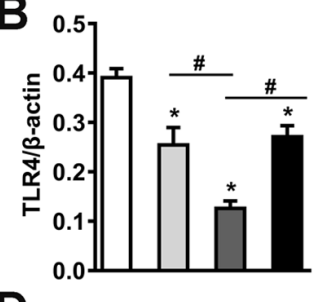

D

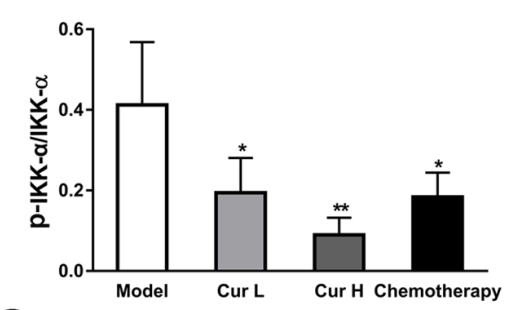

G
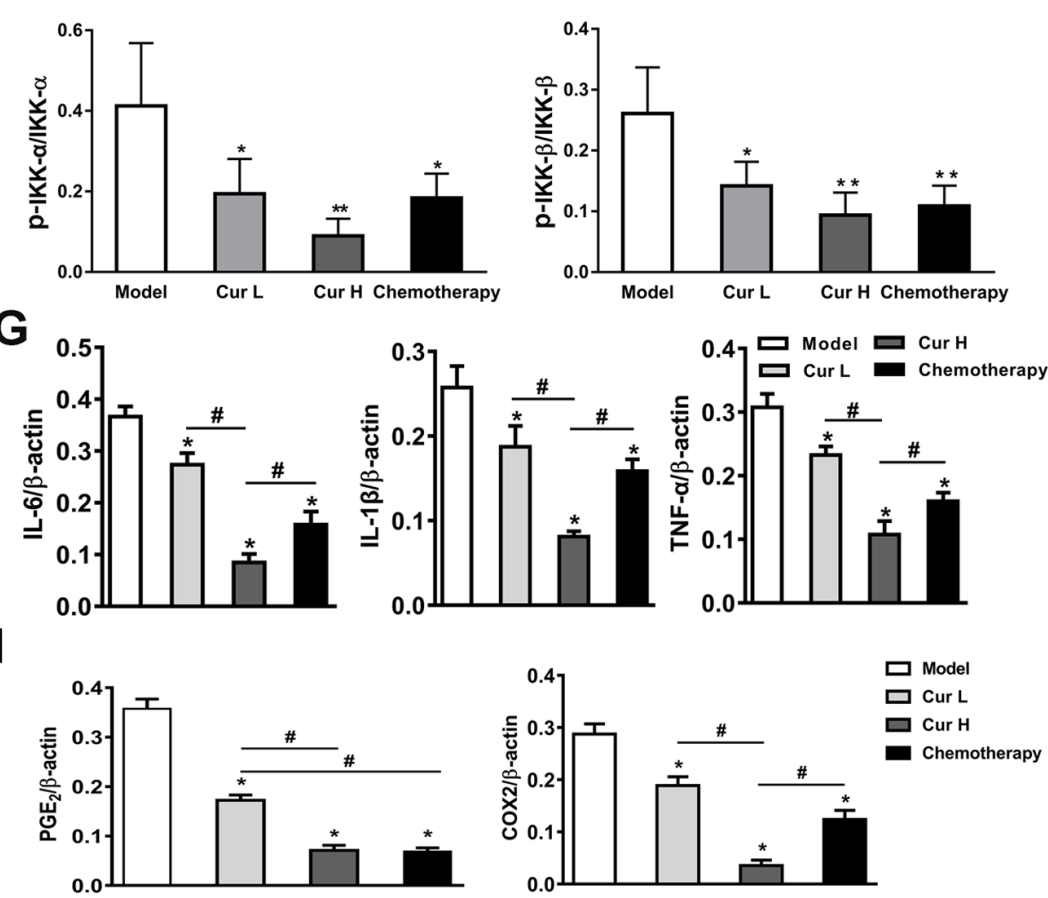

Figure 3. Inhibition of the TLR4/NF-кB signaling pathway-mediated inflammatory response. (A) Western blotting was used to analyze and (B) semi-quantify the expression levels of TLR4, MyD88 and NF-kB in murine tumor tissues. (C) Expression levels and semi-quantitative analysis of (D) IKK- $\alpha$, p-IKK- $\alpha$, (E) IKK- $\beta$ and p-IKK- $\beta$ in murine tumor tissues. (F) Expression levels and (G) semi-quantitative analysis of IL-6, IL-1 $\beta$ and TNF- $\alpha$ in murine tumor tissues. $(\mathrm{H})$ Expression levels and (I) semi-quantitative analysis of PGE2 and COX-2 in murine tumor tissues. Data are presented as the mean \pm SD (n=7). ${ }^{*} \mathrm{P}<0.05$ and ${ }^{* * *} \mathrm{P}<0.01$ vs. model group; ${ }^{*} \mathrm{P}<0.05$, as indicated. TLR4, toll-like receptor 4; MyD88, myeloid differentiation primary response 88; IKK $\alpha$, nuclear

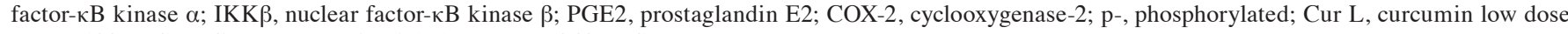
group $(120 \mathrm{mg} / \mathrm{kg})$; Cur H, curcumin high dose group $(240 \mathrm{mg} / \mathrm{kg})$.

signaling pathway and control the inflammatory response, which may be the underlying mechanism inhibiting MDSC activity and thus, inhibiting cancer progression.

Curcumin suppresses tumor angiogenesis. The angiogenic programming of neoplastic tissue is a multidimensional process that is regulated by cancer cells in concert with a variety of tumor-associated stromal cells and their bioactive products. MDSCs promote tumor angiogenesis by producing pro-angiogenic growth factors, such as VEGF (39). The results of the western blot analysis demonstrated that 120 and $240 \mathrm{mg} / \mathrm{kg}$ curcumin, particularly Cur $\mathrm{H}$, significantly downregulated VEGF expression in vivo compared with that in the model group (Fig. 4A). To further verify the anti-angiogenic effect of curcumin in vivo, the excised tumor tissues were analyzed using IHC for CD31 expression (a platelet endothelial cell adhesion molecule) and VEGF, and by immunofluorescence using anti- $\alpha \mathrm{SMC}$ (an arterial smooth muscle cell marker) and anti-CD31 antibodies. The observed downregulated expression levels of VEGF, CD31 and $\alpha \mathrm{SMC}$ in the tumor tissues indicated that angiogenesis may be suppressed by curcumin treatment (Fig. 4B). Overall, these findings indicated that curcumin may inhibit VEGF and CD31-induced angiogenesis in vivo.

\section{Discussion}

Curcumin has been reported to be a promising anticancer agent in various types of cancer. In the present study, data obtained from the xenograft nude mouse model provided further evidence that curcumin effectively suppressed the growth of liver cancer. Similarly, numerous previous in vitro and in vivo studies have demonstrated that curcumin inhibits the growth cancer in both animals and humans (40-42), including hepatocellular carcinoma (43). Several reports have suggested that curcumin or its derivative alone or in combination with other drugs exhibit favorable anti-liver cancer activity (44-46). Shao et al (47) reported that bisdemethoxycurcumin, a natural dimethoxy derivative of curcumin, decreases the number of tumor-infiltrating MDSCs in MB49 metastasized bladder cancer cells. In addition, curcumin could suppress MKN-45 human gastric cancer cell and CT26 mouse colon cancer cell 

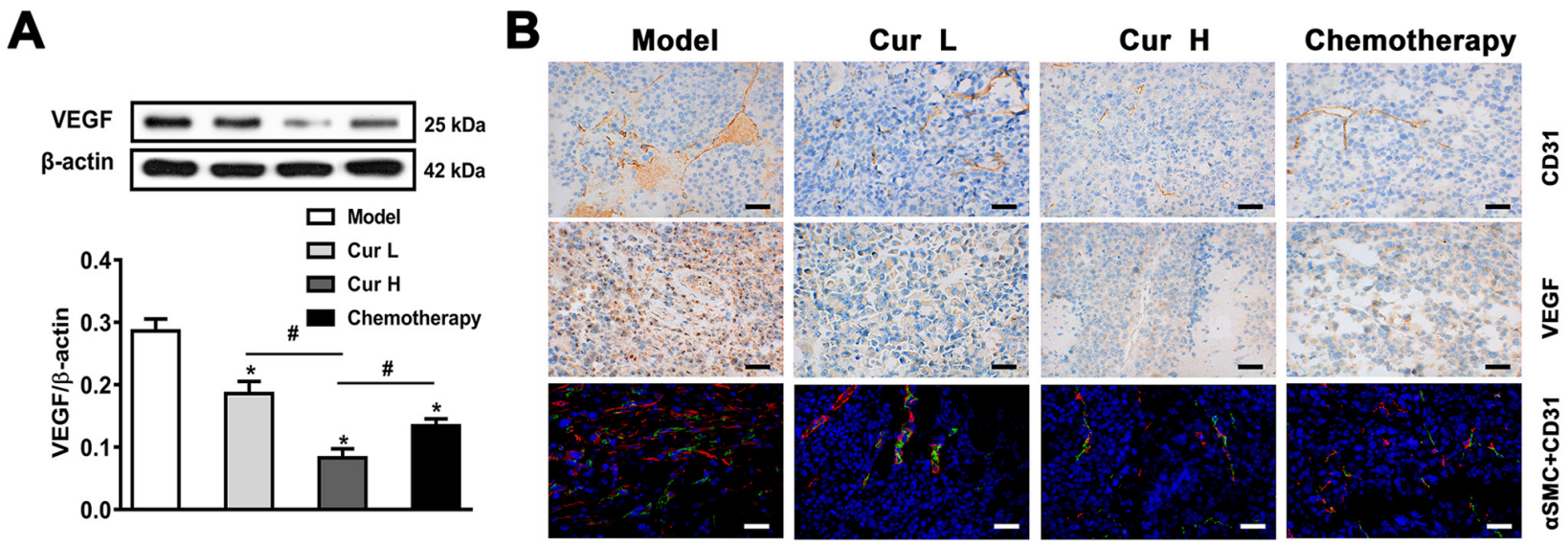

Figure 4. Curcumin suppresses tumor angiogenesis. (A) Western blotting was used to analyze and semi-quantify the expression levels of VEGF. (B) Immunohistochemistry analysis of CD31 and VEGF expression in murine tumor tissues, and immunofluorescence analysis of $\alpha$ SMC and CD31 expression in murine tumor tissues (magnification, $\mathrm{x} 400$; scale bar, $50 \mu \mathrm{m}$ ). Data are presented as the mean $\pm \mathrm{SD}\left(\mathrm{n}=7\right.$ ). ${ }^{*} \mathrm{P}<0.05 \mathrm{vs}$. model group; ${ }^{\prime} \mathrm{P}<0.05$, as indicated. VEGF, vascular endothelial growth factor; $\alpha \mathrm{SMC}, \alpha$-smooth muscle cell actin; Cur L, curcumin low dose group (120 mg/kg); Cur H, curcumin high dose group $(240 \mathrm{mg} / \mathrm{kg})$.

proliferation by blocking the STAT3 and NF- $\mathrm{B}$ signaling pathway-mediated activation and expansion of MDSCs, in addition to the interaction of cancer cells with MDSCs (48). However, to the best of our knowledge, no previous study has investigated the anti-liver cancer activity of curcumin, and in particular the association among inflammation, MDSCs and angiogenesis in tumor tissues. Therefore, the present study was the first to report that the anticancer activity of curcumin may be due to the inactivation of MDSCs, which was associated with the ability of curcumin to inhibit TLR4/NF- $\kappa \mathrm{B}$-mediated inflammation and decrease GM-CSF and G-CSF secretion, which subsequently repressed angiogenesis and tumor growth.

In-depth research on the pathogenesis of cancer has revealed that inflammation and the immune microenvironment are key players in cancer growth, spread and metastasis (49). Defined immune cell subsets have been reported to dictate cancer fate by their expansion and recruitment within the loco-regional tumor microenvironment (50). High numbers of myeloid cells, particularly MDSCs, have been associated with tumor promotion, metastasis and a poor prognosis (2). MDSCs are found in the peripheral blood and solid tumors, where they are known to maintain an immunosuppressive network in the tumor microenvironment $(50,51)$. In particular, they constitute a key checkpoint that prevents an immune response against tumors (51). Previous studies have reported that the inhibition of MDSCs in the tumor may weaken the tumor defense mechanisms and inhibit tumor progression, including in lung cancer (52,53), malignant melanoma (54) and liver cancer (55). Previous evidence has indicated that curcumin suppresses and prevents carcinogenesis via multifaceted molecular targets; however, to the best of our knowledge, there are few studies reporting the role of curcumin in regulating MDSCs (48), particularly in liver cancer.

TDFs, which are mainly cytokines, chemokines and metabolic soluble mediators, promote and sustain the expansion of the heterogeneous population of myeloid cells, skew myeloid cells towards an immunosuppressive phenotype and endow them with regulatory functions (2). TDFs, such as GM-CSF, G-CSF and inflammatory factors (TNF- $\alpha$, IL-1 $\beta$ and IL-6), are crucial mediators in MDSC modulation (4). G-CSF and GM-CSF have been discovered to be the main regulators of the proliferation and differentiation of myeloid cells (56). A recent study demonstrated that cancer cell-derived GM-CSF serves a key role in cancer progression, and GM-CSF is indispensable for the tuning of the tumor microenvironment and MDSCs (57). Furthermore, the inflammatory microenvironment in cancer, which is established by multiple inflammatory factors, recruits and activates MDSCs (58). The results of the present study revealed that curcumin markedly suppressed the levels of M-CSF, GM-CSF and numerous inflammatory factors, which provided evidence for the inhibitory effect of curcumin on MDSCs and its subsequent anti-liver cancer activity.

The immunosuppressive potential of MDSCs is mainly dependent on the expression of inflammation-related proteins (59). TLR4/NF- $\kappa \mathrm{B}$ is a canonical inflammatory signaling pathway that has a prominent role in mediating the inflammatory response in multiple types of disease, including cancer (12). Activated TLR4 interacts with MyD88, and then induces IKK phosphorylation (18). IKK phosphorylation triggers the activation of $\mathrm{NF}-\kappa \mathrm{B}$, which in turn promotes the expression of inflammation- and immune-suppressive signaling pathway genes (60). Several previous studies have demonstrated that the TLR4 axis enhances the immunosuppressive function of MDSCs (61) and that curcumin inhibits liver cancer via the TLR4/NF- $\kappa \mathrm{B}$ signaling pathway (62). The present study investigated whether curcumin alleviated the MDSC-mediated immunosuppressive function via the TLR4/NF- $\kappa \mathrm{B}$ signaling pathway. The data revealed that curcumin treatment decreased the protein expression levels of TLR4, MyD88, p-IKK and NF- $\mathrm{BB}$. This indicated that curcumin may inactivate the TLR4/NF- $\kappa \mathrm{B}$ signaling pathway, which may in turn result in a decreased inflammatory response.

In addition, MDSCs promote tumor angiogenesis by producing pro-angiogenic growth factors, such as VEGF, and endothelial cell adhesion molecules, such as CD31 (63). Additionally, the inhibition of inflammatory factors, such as IL-6, has been associated with the attenuation of 


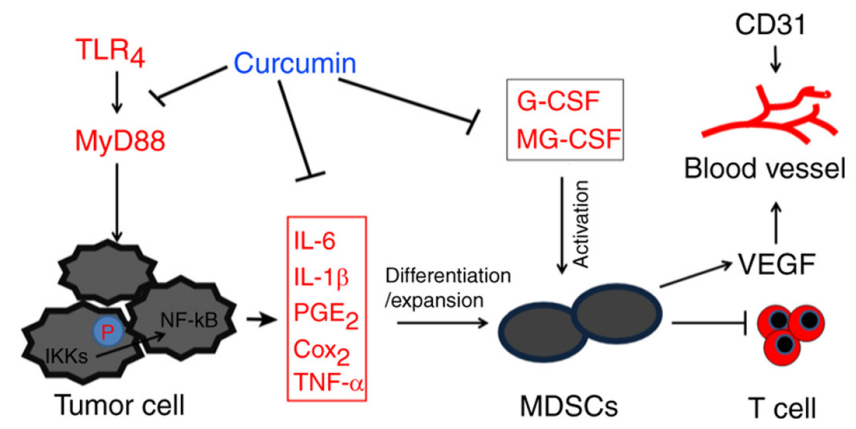

Figure 5. Schematic diagram of the inhibitory effect of curcumin on MDSCs and liver cancer. Curcumin exerted an inhibitory effect on MDSCs by inhibiting the TLR4/NF-kB-mediated inflammatory microenvironment and attenuating G-CSF and GM-CSF secretion. This subsequently suppresses tumor angiogenesis and ameliorates immune tolerance in liver cancer, thus exhibiting anti-liver cancer effects. TLR4, toll-like receptor 4; MyD88, myeloid differentiation primary response 88 ; IKK, nuclear factor- $\kappa \mathrm{B}$ kinase; PGE2, prostaglandin E2; COX-2, cyclooxygenase-2; MDSCs, myeloid-derived suppressor cells; G-CSF, granulocyte-colony stimulating factor; GM-CSF, granulocyte-macrophage colony-stimulating factor; VEGF vascular endothelial growth factor.

angiogenesis (64). In a previous study, curcumin inhibited hepatocellular carcinoma growth by downregulating VEGF expression (65). Similarly, the present results demonstrated that curcumin treatment suppressed angiogenesis by downregulating VEGF and CD31 expression in the tumor tissues, which was demonstrated using western blotting, IHC and immunofluorescence staining experiments. These results might be attributed to the inhibitory effect of curcumin on MDSCs and inflammation.

The doses of curcumin used in the present study were selected based on our preliminary experiment and a pervious study (33). In addition, 120 and $240 \mathrm{mg} / \mathrm{kg}$ curcumin used in mice is equivalent to $\sim 0.65$ and $1.3 \mathrm{~g} / \mathrm{day}$, respectively, in humans, based on the mouse/human dose conversion coefficient. Furthermore, a phase I clinical trial has demonstrated that curcumin is safe even at high doses (12 g/day) in humans (34). Therefore, from the perspective of safety, the dosage is acceptable when it comes to humans. In respect to efficacy, curcumin could efficaciously delay liver cancer growth, almost equivalent to the chemotherapy group. Even marketed anticancer drugs, such as sorafenib and lenvatinib, cannot prevent the growth of liver cancer (66). Therefore, the anti-liver cancer effect of curcumin revealed in the present study is of values. Importantly, the present study revealed a novel mechanism in which curcumin suppressed the growth of liver cancer by impairing MDSCs in murine tumor tissues.

Although curcumin is deemed safe and nontoxic, even at high doses (12 g/day), in humans, the low aqueous solubility, poor absorption and rapid metabolism of curcumin severely impedes its bioavailability and thus, prevents its application as a therapeutic agent $(34,67)$. To overcome this challenge, various strategies have been explored, including the alteration of the administration route of curcumin, blocking the metabolism of curcumin with other agents, altering the structural modifications of curcumin and investigating the possibility of oral delivery systems $(34,68)$. Among them, oral delivery systems, a novel delivery strategy established in recent years, has offered significant promise in enhancing the bioavailability of curcumin, and this involves the use of nano and microparticles, polymeric micelles, nanosuspensions or lipid-based nanocarriers $(67,69)$. Further studies should aim to introduce the aforementioned bioavailable curcumin-based formulations to explore the efficacy of the anti-liver cancer effects of curcumin through this delivery method, with a specific focus on its ability to affect inflammation, MDSCs and their interactions.

There are certain limitations of the present study: i) The HepG2 cell line was not authenticated; ii) in vivo imaging of tumors and Kaplan-Meier curves of mice were not provided; iii) no information was provided regarding the effectiveness of either curcumin or chemotherapy on tumor once the treatment was discontinued; and iv) the effect of curcumin on the TLR4/NF- $\kappa$ B signaling pathway in isolated MDSCs from xenografts was not determined. Based on the aforementioned limitations, in future research, authentication of HepG2 cells is warranted, Kaplan-Meier curves, in vivo imaging of tumors, and a prolonged period of time effectiveness of curcumin, particularly once the treatment is discontinued, should be provided to comprehensively evaluate the effect of curcumin on liver cancer. MDSCs should be isolated from xenografts and IKK activator should be applied to examine whether curcumin exerts its anti-liver cancer effect via blocking of the TLR4/NF- $\mathrm{B}$ signaling pathway in MDSCs.

In conclusion, the findings of the present study indicated that curcumin may effectively prevent liver cancer by impairing MDSCs in tumor tissues, which was demonstrated by the inhibition of GM-CSF and G-CSF secretion, and TLR4/NF-кB-mediated inflammation (Fig. 5). The present study provided novel insights into the anti-liver cancer mechanism of curcumin and a theoretical basis for anti-liver cancer drug development targeting MDSCs.

\section{Acknowledgements}

The authors would like to thank Dr Yiming Tao (Xiangya Medical College, Central South University, Changsha, China) for providing the reagents used in the present study and for help revising the manuscript.

\section{Funding}

The present study was supported by grants from the National Natural Science Foundation of China (grant no. 81473617), the Science and Technology Department of Hunan Province (grant no. 2017SK50310), the Innovation Platform Open Foundation of Hunan Educational office (grant no. 16K066) and Hunan Province 'domestic first-class cultivation discipline' Integrated Traditional Chinese and Western medicine open fund project (2018ZXYJH03, 2019ZXJH02).

\section{Availability of data and materials}

The datasets used and/or analyzed during the current study are available from the corresponding author on reasonable request.

\section{Authors' contributions}

XT conceived, designed and guided the study. ST and LL performed the experiments. QZ, XH, PZ and YG analyzed 
the data and generated the graphs. TD and XT helped analyze the experimental results and provided technical guidance. XT and ST drafted the manuscript. XT and ST are responsible for confirming the authenticity of all the raw data. All authors read and approved the final manuscript.

\section{Ethics approval and consent to participate}

All experimental protocols were approved by the Institute Review Board of Xiangya Medical College (Changsha, China).

\section{Patient consent for publication}

Not applicable.

\section{Competing interests}

The authors declare that they have no competing interests.

\section{References}

1. Galon J, Costes A, Sanchez-Cabo F, Kirilovsky A, Mlecnik B, Lagorce-Pagès $\mathrm{C}$, Tosolini $\mathrm{M}$, Camus $\mathrm{M}$, Berger $\mathrm{A}$, Wind $\mathrm{P}$, et al: Type, density, and location of immune cells within human colorectal tumors predict clinical outcome. Science 313 1960-1964, 2006.

2. Condeelis J and Pollard JW: Macrophages: Obligate partners for tumor cell migration, invasion, and metastasis. Cell 124 263-266, 2006.

3. Movahedi K, Guilliams M, Van den Bossche J, Van den Bergh R, Gysemans C, Beschin A, De Baetselier P and Van Ginderachter JA: Identification of discrete tumor-induced myeloid-derived suppressor cell subpopulations with distinct T cell-suppressive activity. Blood 111: 4233-4244, 2008.

4. De Sanctis F, Solito S, Ugel S, Molon B, Bronte V and Marigo I: MDSCs in cancer: Conceiving new prognostic and therapeutic targets. Biochim Biophys Acta 1865: 35-48, 2016.

5. Watson GA, Fu YX and Lopez DM: Splenic macrophages from tumor-bearing mice co-expressing MAC-1 and MAC-2 antigens exert immunoregulatory functions via two distinct mechanisms. J Leukoc Biol 49: 126-138, 1991.

6. Kidiyoor A, Schettini J, Besmer DM, Rego SL, Nath S, Curry JM, Roy LD, Dréau D and Mukherjee P: Pancreatic cancer cells isolated from Mucl-null tumors favor the generation of a mature less suppressive MDSC population. Front Immunol 5: 67, 2014.

7. Gutschalk CM, Yanamandra AK, Linde N, Meides A, Depner S and Mueller MM: GM-CSF enhances tumor invasion by elevated MMP-2, -9, and -26 expression. Cancer Med 2: 117-129, 2013.

8. Kowanetz M, Wu X, Lee J, Tan M, Hagenbeek T, Qu X, Yu L, Ross J, Korsisaari N, Cao T, et al: Granulocyte-colony stimulating factor promotes lung metastasis through mobilization of Ly6G+Ly6C+ granulocytes. Proc Natl Acad Sci USA 107: 21248-21255, 2010.

9. Quail DF, Olson OC, Bhardwaj P, Walsh LA, Akkari L, Quick ML, Chen IC, Wendel N, Ben-Chetrit N, Walker J, et al: Obesity alters the lung myeloid cell landscape to enhance breast cancer metastasis through IL5 and GM-CSF. Nat Cell Biol 19: 974-987, 2017

10. Serafini P, Carbley R, Noonan KA, Tan G, Bronte V and Borrello I: High-dose granulocyte-macrophage colony-stimulating factor-producing vaccines impair the immune response through the recruitment of myeloid suppressor cells. Cancer Res 64 6337-6343, 2004

11. Dolcetti L, Peranzoni E, Ugel S, Marigo I, Fernandez Gomez A, Mesa C, Geilich M, Winkels G, Traggiai E, Casati A, et al: Hierarchy of immunosuppressive strength among myeloid-derived suppressor cell subsets is determined by GM-CSF. Eur J Immunol 40: 22-35, 2010.

12. Yao D, Dong M, Dai C and Wu S: Inflammation and inflammatory cytokine contribute to the initiation and development of ulcerative colitis and its associated cancer. Inflamm Bowel Dis 25: 1595-1602, 2019.
13. Xu J, Pei S, Wang Y, Liu J, Qian Y, Huang M, Zhang Y and Xiao Y: Tpl2 protects against fulminant hepatitis through mobilization of myeloid-derived suppressor cells. Front Immunol 10: 1980, 2019.

14. Li ZW, Sun B, Gong T, Guo S, Zhang J, Wang J, Sugawara A, Jiang M, Yan J, Gurary A, et al: GNAI1 and GNAI3 reduce colitis-associated tumorigenesis in mice by blocking il6 signaling and down-regulating expression of GNAI2. Gastroenterology 156: 2297-2312, 2019.

15. Tariq M, Zhang J, Liang G, Ding L, He Q and Yang B: Macrophage polarization: Anti-cancer strategies to target tumor-associated macrophage in breast cancer. J Cell Biochem 118: 2484-2501, 2017.

16. Musolino C, Allegra A, Pioggia G and Gangemi S: Immature myeloid-derived suppressor cells: A bridge between inflammation and cancer (Review). Oncol Rep 37: 671-683, 2017.

17. Perfilyeva YV, Abdolla N, Ostapchuk YO, Tleulieva R, Krasnoshtanov VC, Perfilyeva AV and Belyaev NN: Chronic inflammation contributes to tumor growth: Possible role of l-selectin-expressing myeloid-derived suppressor cells (MDSCs). Inflammation 42: 276-289, 2019.

18. Guven Maiorov E, Keskin O, Gursoy A and Nussinov R: The structural network of inflammation and cancer: Merits and challenges. Semin Cancer Biol 23: 243-251, 2013

19. Wang L, Niu Z, Wang X, Li Z, Liu Y, Luo F and Yan X: PHD2 exerts anti-cancer and anti-inflammatory effects in colon cancer xenografts mice via attenuating $\mathrm{NF}-\kappa \mathrm{B}$ activity. Life Sci 242 : 117167,2020

20. Banerjee S, Ji C, Mayfield JE, Goel A, Xiao J, Dixon JE and Guo X: Ancient drug curcumin impedes $26 \mathrm{~S}$ proteasome activity by direct inhibition of dual-specificity tyrosine-regulated kinase 2. Proc Natl Acad Sci USA 115: 8155-8160, 2018.

21. Liu Y, Wang X, Zeng S, Zhang X, Zhao J, Zhang X, Chen X, Yang W, Yang Y, Dong Z, et al: The natural polyphenol curcumin induces apoptosis by suppressing STAT3 signaling in esophageal squamous cell carcinoma. J Exp Clin Cancer Res 37: 303, 2018

22. Zhang P, Lai ZL, Chen HF, Zhang M, Wang A, Jia T, Sun WQ, Zhu XM, Chen XF, Zhao Z and Zhang J: Curcumin synergizes with 5-fluorouracil by impairing AMPK/ULK1-dependent autophagy, AKT activity and enhancing apoptosis in colon cancer cells with tumor growth inhibition in xenograft mice. J Exp Clin Cancer Res 36: 190, 2017.

23. Wang L, Chen X, Du Z, Li G, Chen M, Chen X, Liang G and Chen T: Curcumin suppresses gastric tumor cell growth via ROS-mediated DNA polymerase $\gamma$ depletion disrupting cellular bioenergetics. J Exp Clin Cancer Res 36: 47, 2017.

24. Rana M, Maurya P, Reddy SS, Singh V, Ahmad H, Dwivedi AK, Dikshit M and Barthwal MK: A standardized chemically modified Curcuma longa extract modulates IRAK-MAPK signaling in inflammation and potentiates cytotoxicity. Front Pharmacol 7: $223,2016$.

25. Uchio R, Higashi Y, Kohama Y, Kawasaki K, Hirao T, Muroyama $\mathrm{K}$ and Murosaki S: A hot water extract of turmeric (Curcuma longa) suppresses acute ethanol-induced liver injury in mice by inhibiting hepatic oxidative stress and inflammatory cytokine production. J Nutr Sci 6: e3, 2017.

26. Farajzadeh R, Zarghami N, Serati-Nouri H, Momeni-Javid Z, Farajzadeh T, Jalilzadeh-Tabrizi S, Sadeghi-Soureh S, Naseri N and Pilehvar-Soltanahmadi Y: Macrophage repolarization using CD44-targeting hyaluronic acid-polylactide nanoparticles containing curcumin. Artif Cells Nanomed Biotechnol 46: 2013-2021, 2018

27. Illuri R, Bethapudi B, Anandakumar S, Murugan S, Joseph JA, Mundkinajeddu D, Agarwal A and Chandrasekaran CV: Anti-Inflammatory activity of polysaccharide fraction of Curcuma longa extract (NR-INF-02). Antiinflamm Antiallergy Agents Med Chem 14: 53-62, 2015.

28. Kocaadam B and Şanlier N: Curcumin, an active component of turmeric (Curcuma longa), and its effects on health. Crit Rev Food Sci Nutr 57: 2889-2895, 2017.

29. Pulido-Moran M, Moreno-Fernandez J, Ramirez-Tortosa C and Ramirez-Tortosa M: Curcumin and health. Molecules 21: 264, 2016.

30. Darvesh AS, Aggarwal BB and Bishayee A: Curcumin and liver cancer: A review. Curr Pharm Biotechnol 13: 218-228, 2012.

31. National Research Council: Guide for the Care and Use of Laboratory Animals. The National Academies Press, Washington DC, USA, eighth edition, pp 11-154, 2011. 
32. Kolligs FT, Hoffmann RT, op den Winkel M, Bruns CJ, Herrmann K, Jakobs TF, Lamerz R, Trumm C, Zech CJ, Wilkowski R and Graeb C: Diagnosis and multimodal therapy for hepatocellular carcinoma. Z Gastroenterol 48: 274-288, 2010 (In German).

33. Hu P, Ke C, Guo X, Ren P, Tong Y, Luo S, He Y, Wei Z, Cheng B, $\mathrm{Li}$, et al: Both glypican-3/Wnt/ $\beta$-catenin signaling pathway and autophagy contributed to the inhibitory effect of curcumin on hepatocellular carcinoma. Dig Liver Dis 51: 120-126, 2019.

34. Anand P, Kunnumakkara AB, Newman RA and Aggarwal BB: Bioavailability of curcumin: Problems and promises. Mol Pharm 4: 807-818, 2007.

35. Karova K, Wainwright JV, Machova-Urdzikova L, Pisal RV, Schmidt M, Jendelova P and Jhanwar-Uniyal M: Transplantation of neural precursors generated from spinal progenitor cells reduces inflammation in spinal cord injury via NF- $\kappa$ B pathway inhibition. J Neuroinflammation 16: 12, 2019.

36. Gabrilovich DI: Myeloid-derived suppressor cells. Cancer Immunol Res 5: 3-8, 2017.

37. Rafa H, Benkhelifa S, AitYounes S, Saoula H, Belhadef S, Belkhelfa M, Boukercha A, Toumi R, Soufli I, Moralès O, et al: All-Trans retinoic acid modulates TLR4/NF- $\kappa \mathrm{B}$ signaling pathway targeting TNF- $\alpha$ and nitric oxide synthase 2 expression in colonic mucosa during ulcerative colitis and colitis associated cancer. Mediators Inflamm 2017: 7353252, 2017.

38. Cheng R, Billet S, Liu C, Haldar S, Choudhury D, Tripathi M, Hav M, Merchant A, Hu T, Huang H, et al: Periodontal inflammation recruits distant metastatic breast cancer cells by increasing myeloid-derived suppressor cells. Oncogene 39: 1543-1556, 2020

39. Ching MM, Reader J and Fulton AM: Eicosanoids in cancer: Prostaglandin E(2) receptor 4 in cancer therapeutics and immunotherapy. Front Pharmacol 11: 819, 2020.

40. Liu Q, Yuan JW, Zhang F, Qiao F, Sui XF and Liu CH: Curcumin protects rat $\mathrm{H} 9 \mathrm{C} 2$ cardiomyocytes against doxorubicin toxicity by modulating oxidative stress and apoptosis. J Biol Regul Homeost Agents 33: 1849-1854, 2019.

41. Flores-Pérez JA, de la Rosa Oliva F, Argenes Y and Meneses-Garcia A: Nutrition, cancer and personalized medicine. Adv Exp Med Biol 1168: 157-168, 2019.

42. Willenbacher E, Khan SZ, Mujica SCA, Trapani D, Hussain S, Wolf D, Willenbacher W, Spizzo G and Seeber A: Curcumin: New insights into an ancient ingredient against cancer. Int J Mol Sci 20: 1808, 2019

43. Kong ZL, Kuo HP, Johnson A, Wu LC and Chang KLB Curcumin-loaded mesoporous silica nanoparticles markedly enhanced cytotoxicity in hepatocellular carcinoma cells. Int J Mol Sci 20: 2918, 2019.

44. Wang L, Zhu Z, Han L, Zhao L, Weng J, Yang H, Wu S, Chen $\mathrm{K}, \mathrm{Wu} \mathrm{L}$ and Chen T: A curcumin derivative, WZ35, suppresses hepatocellular cancer cell growth via downregulating YAP-mediated autophagy. Food Funct 10: 3748-3757, 2019.

45. Shao S, Duan W, Xu Q, Li X, Han L, Li W, Zhang D, Wang Z and Lei J: Curcumin suppresses hepatic stellate cell-induced hepatocarcinoma angiogenesis and invasion through downregulating CTGF. Oxid Med Cell Longev 2019: 8148510, 2019.

46. Tang D, Zhang S, Shi X, Wu J, Yin G, Tan X, Liu F, Wu X and Du X Combination of astragali polysaccharide and curcumin improves the morphological structure of tumor vessels and induces tumor vascular normalization to inhibit the growth of hepatocellular carcinoma. Integr Cancer Ther 18: 1534735418824408, 2019.

47. Shao Y, Zhu W, Da J, Xu M, Wang Y, Zhou J and Wang Z: Bisdemethoxycurcumin in combination with $\alpha-\mathrm{PD}-\mathrm{L} 1$ antibody boosts immune response against bladder cancer. Onco Targets Ther 10: 2675-2683, 2017

48. Tu SP, Jin H, Shi JD, Zhu LM, Suo Y, Lu G, Liu A, Wang TC and Yang CS: Curcumin induces the differentiation of myeloid-derived suppressor cells and inhibits their interaction with cancer cells and related tumor growth. Cancer Prev Res (Phila) 5: 205-215, 2012.

49. Keren L, Bosse M, Marquez D, Angoshtari R, Jain S, Varma S Yang SR, Kurian A, Van Valen D, West R, et al: A structured tumor-immune microenvironment in triple negative breast cancer revealed by multiplexed ion beam imaging. Cell 174 $1373-1387,2018$

50. Lazăr DC, Avram MF, Romosan I, Cornianu M, Tăban S and Goldis A: Prognostic significance of tumor immune microenvironment and immunotherapy: Novel insights and future perspectives in gastric cancer. World J Gastroenterol 24 $3583-3616,2018$
51. Salminen A: Activation of immunosuppressive network in the aging process. Ageing Res Rev 57: 100998, 2020.

52. Liu D, You M, Xu Y, Li F, Zhang D, Li X and Hou Y: Inhibition of curcumin on myeloid-derived suppressor cells is requisite for controlling lung cancer. Int Immunopharmacol 39: 265-272, 2016

53. Li YD, Lamano JB, Lamano JB, Quaggin-Smith J, Veliceasa D, Kaur G, Biyashev D, Unruh D and Bloch O: Tumor-induced peripheral immunosuppression promotes brain metastasis in patients with non-small cell lung cancer. Cancer Immunol Immunother 68: 1501-1513, 2019.

54. Hutchison S, Sahay B, de Mello SC, Sayour EJ, Lejeune A, Szivek A, Livaccari AM, Fox-Alvarez S, Salute M, Powers L and Milner RJ: Characterization of myeloid-derived suppressor cells and cytokines GM-CSF, IL-10 and MCP-1 in dogs with malignant melanoma receiving a GD3-based immunotherapy. Vet Immunol Immunopathol 216: 109912, 2019.

55. Xu Y, Fang F, Jiao H, Zheng X, Huang L, Yi X and Zhao W: Activated hepatic stellate cells regulate MDSC migration through the SDF-1/CXCR4 axis in an orthotopic mouse mode of hepatocellular carcinoma. Cancer Immunol Immunother 68 1959-1969, 2019

56. Al Sayed MF, Amrein MA, Bührer ED, Huguenin AL, Radpour R, Riether $\mathrm{C}$ and Ochsenbein AF: T-cell-secreted TNFa induces emergency myelopoiesis and myeloid-derived suppressor cell differentiation in cancer. Cancer Res 79: 346-359, 2019

57. Yoshimura T, Nakamura K, Li C, Fujisawa M, Shiina T, Imamura M, Li T, Mukaida N and Matsukawa A: Cancer cell-derived granulocyte-macrophage colony-stimulating factor is dispensable for the progression of $4 \mathrm{t} 1$ murine breast cancer. Int J Mol Sci 20: 6324, 2019.

58. Chen L, Huang CF, Li YC, Deng WW, Mao L, Wu L, Zhang WF, Zhang L and Sun ZJ: Blockage of the NLRP3 inflammasome by MCC950 improves anti-tumor immune responses in head and neck squamous cell carcinoma. Cell Mol Life Sci 75: 2045-2058, 2018.

59. Bronte V, Brandau S, Chen SH, Colombo MP, Frey AB, Greten TF Mandruzzato S, Murray PJ, Ochoa A, Ostrand-Rosenberg S, et al: Recommendations for myeloid-derived suppressor cell nomenclature and characterization standards. Nat Commun 7: 12150, 2016.

60. Lei R, Li J, Liu F, Li W, Zhang S, Wang Y, Chu X and Xu J: HIF-1 $\alpha$ promotes the keloid development through the activation of TGF- $\beta /$ Smad and TLR4/MyD88/NF- $\mathrm{BB}$ pathways. Cell Cycle 18: 3239-3250, 2019.

61. Tachibana M: The immunosuppressive function of myeloidderived suppressor cells is regulated by the HMGB1-TLR4 axis. Yakugaku Zasshi 138: 143-148, 2018 (In Japanese)

62. Ren B, Luo S, Tian X, Jiang Z, Zou G, Xu F, Yin T, Huang Y and Liu J: Curcumin inhibits liver cancer by inhibiting DAMP molecule HSP70 and TLR4 signaling. Oncol Rep 40: 895-901, 2018.

63. Cassino TR, Drowley L, Okada M, Beckman SA, Keller B, Tobita K, Leduc PR and Huard J: Mechanical loading of stem cells for improvement of transplantation outcome in a model of acute myocardial infarction: The role of loading history. Tissue Eng Part A 18: 1101-1108, 2012.

64. Tawara K, Scott H, Emathinger J, Ide A, Fox R, Greiner D, LaJoie D, Hedeen D, Nandakumar M, Oler AJ, et al: Co-expression of VEGF and IL-6 family cytokines is associated with decreased survival in HER2 negative breast cancer patients: Subtype-specific IL-6 family cytokine-mediated VEGF secretion. Transl Oncol 12: 245-255, 2019.

65. Pan Z, Zhuang J, Ji C, Cai Z, Liao W and Huang Z: Curcumin inhibits hepatocellular carcinoma growth by targeting VEGF expression. Oncol Lett 15: 4821-4826, 2018.

66. Forner A, Reig M and Bruix J: Hepatocellular carcinoma. Lancet 391: 1301-1314, 2018.

67. Ma Z, Wang N, He H and Tang X: Pharmaceutical strategies of improving oral systemic bioavailability of curcumin for clinical application. J Control Release 316: 359-380, 2019.

68. Liu W, Zhai Y, Heng X, Che FY, Chen W, Sun D and Zhai G: Oral bioavailability of curcumin: Problems and advancements. J Drug Target 24: 694-702, 2016

69. Salehi M, Movahedpour A, Tayarani A, Shabaninejad Z, Pourhanifeh MH, Mortezapour E, Nickdasti A, Mottaghi R, Davoodabadi A, Khan $\mathrm{H}$, et al: Therapeutic potentials of curcumin in the treatment of non-small-cell lung carcinoma. Phytother Res 34: 2557-2576, 2020.

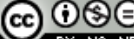

This work is licensed under a Creative Commons Attribution-NonCommercial-NoDerivatives 4.0 International (CC BY-NC-ND 4.0) License. 